\title{
“That's Just How We Say it": Understanding L2 Student Writers' Responses to Written and Negotiated Corrective Feedback Through Critical Incidents
}

\author{
Emma R. Britton \& Theresa Y. Austin
}

According to sociocultural theory (SCT), corrective feedback (CF) entails a negotiation process whereby writing instructors support second language (L2) writers in self-correction and provide a level of guidance needed for writers to actively engage in revision tasks (Aljaafreh $\mathcal{E}$ Lantolf, 1994). Drawing on SCT, this collaborative self-study details the CF experiences of one writing instructor and four L2 students. Focusing on six "critical incidents" occurring within the instructor's teaching context (a developmental writing course in a Northeastern U.S. university), the authors investigate L2 writers' responses to written (WCF) and negotiated oral CF. During these incidents, students engaged with different forms of CF. The authors' analysis of these incidents draws attention to the micro- and macro-contextual features that complicate students' uptake and perceptions about differing forms of CF. Findings reveal the importance of faceto-face negotiation in resolving lexicogrammatical issues. Despite some students' successful uptake of WCF, the paper argues that negotiated feedback provides L2 writers with additional opportunities to develop writing identities and to assert their writerly agency. Pedagogical implications are discussed.

Selon la théorie socioculturelle (TSC), la rétroaction corrective (RC) implique un processus de négociation par lequel les instructeurs en rédaction soutiennent les rédacteurs de langue seconde (L2) pour s'autocorriger et fournissent un niveau de conseils nécessaire pour que les rédacteurs s'impliquent activement dans les tâches de révision (Aljaafreh E Lantolf, 1994). En s'inspirant de TSC, cette autoévaluation collaborative décrit en détail les expériences de $R C$ d'un instructeur en rédaction et de quatre étudiants de L2. En se concentrant sur six "événements critiques " qui se sont produits dans le contexte d'enseignement de l'instructeur (un cours de développement des habiletés de rédaction dans une université du nord-est des États-Unis), les auteurs ont enquêté sur les réactions des rédacteurs de $L 2$ à la rétroaction corrective par écrit et à la rétroaction négociée orale. Lors de ces événements, les étudiants ont participé à plusieurs formes de RC. L'analyse que les auteurs font de ces événements attire l'attention sur les caractéristiques microcontextuelles et macrocontextuelles qui compliquent l'assimilation et les perceptions des étudiants par rapport aux différentes formes de RC. Les résultats montrent l'importance de la négociation face-à-face pour résoudre les problèmes lexicogrammaticaux. Malgré l'assimilation réussie de la 
$R C$ écrite par certains étudiants, cet article avance que la rétroaction négociée fournit aux rédacteurs plus d'occasions de développer leur identité de rédacteur et d'affirmer leur activité d'écrivain. L'article discute des implications pédagogiques.

Keywords: written corrective feedback, sociocultural theory, negotiation, critical incident, selfstudy, agency

Most English as a Second Language (ESL) teachers believe that they should correct their students' written language, and many ESL students similarly view language correction as one of the teacher's roles (Ferris, 1995; Razfar, 2010). Yet many teachers wonder how to support students' agency as writers, while providing corrective feedback (CF) on their writing (Guénette, 2013; Shapiro et al., 2016). This paper illustrates one instructor's search to answer this question and deepen her students' involvement with CF. It showcases the instructor's process of increasing her knowledge of the different $\mathrm{CF}$ forms available, combining different $\mathrm{CF}$ forms together, and examining students' responses to these forms.

The objective of this self-study is therefore to expand classroomgenerated knowledge about the different forms of $\mathrm{CF}$ teachers provide to L2 writers, by investigating students' responses to CF. Working in the context of a developmental writing course in a Northeastern U.S. university, the instructor, the first author of this paper, systematically provided indirect written CF on four in-process drafts composed by $34 \mathrm{~L} 2$ writers over a oneyear period. Subsequently during class time, both students and instructor selected additional sentences from in-process drafts and negotiated these together. After the course concluded, the instructor conducted semistructured interviews with focal students, employing think-aloud protocols to further examine how they responded to $\mathrm{CF}$.

To examine how four learners responded to both forms of feedback, we draw on sociocultural theory (SCT) in second language development and critical incident analysis (CIA) as a tool for data selection and analysis. As SCT conceptualizes learning as occurring in interaction, SCT studies focus on the interactional dimensions of the CF process, considering how feedback is carried through with learners and how agency is coproduced (Charteris \& Smardon, 2018; Cumming, 2016). CIA facilitates the representation and interpretation of data. Traditionally, "critical incidents" are representational devices that enable instructors to make sense of firsthand interactions with students (Farrell, 2013). Critical incidents also represent students' points of view, including their perceptions about the CF they received (Halquist \& Musanti, 2010).

As Kartchava (2016) notes, focusing on learners' perceptions of CF is mutually beneficial to instructors and students. Instructors benefit from 
knowing students' "contextually specific expectations and needs," to provide information that students receive positively (p. 20). Students benefit from identifying and developing their perceptions to understand how they may approach and learn from the CF they receive. To this end, the study addresses the following questions:

- How do students respond to and perceive the differing forms of indirect $\mathrm{CF}$ they receive in relation to their writing?

- How do students respond to and perceive negotiated oral CF?

- How does writerly agency emerge as students respond to $\mathrm{CF}$ ?

We begin with a conceptual review, outlining the CF and SCT concepts that informed these research questions. Subsequently, we introduce our methodology, data sources, and analytic procedures, including the selection of six "critical incidents."

\section{Conceptual Framework}

\section{Conceptualizing WCF}

WCF is any input provided to the learner on perceived "error(s)" through a written modality rather than through a verbal modality. Ferris (2011) defines "errors" as "morphological, syntactic, and lexical forms" that diverge from readers' expectations of the target language rules (p. 3). While there is a debate about whether WCF has any value (Truscott, 1999), there is a general consensus in the WCF literature that WCF is useful and valued, particularly by L2 students who having been socialized to error correction and have come to expect it from their writing instructors (Ferris, 2011; Montgomery \& Baker, 2007). This paper argues that these expectations construct what students and teachers may perceive as "good teaching" (but see Goldstein, 2016, for a review of reactions and preferences that $\mathrm{L} 2$ writers express towards WCF). Therefore, research on teaching to these expectations has focused on examining the effectiveness of differing WCF forms (for an overview see Wang \& Jiang, 2015).

Various WCF forms can be distinguished based on two related continuums: directness and explicitness. Drawing on WCF research (i.e., Ferris, 2011; Storch \& Wigglesworth, 2010), Table 1 summarizes the distinctions between these continuums. While WCF studies have obtained contrasting results, demonstrating merits for both direct and indirect approaches (Baker \& Hansen Bricker, 2010), Ferris (2011) argues that indirect feedback is important because it drives "students to be more reflective and analytical about their errors," engaging them in problem-solving processes (p. 94). 
Table 1

Direct and Indirect Approaches to WCF

\begin{tabular}{|c|c|c|}
\hline \multirow[b]{2}{*}{ Direct } & \multicolumn{2}{|c|}{ Indirect } \\
\hline & Implicit strategies & Explicit strategies \\
\hline $\begin{array}{l}\text { Reformulating portions } \\
\text { of the text (i.e., } \\
\text { rewriting) } \\
\text { - Inserting a correction } \\
\text { Providing a command } \\
\text { for a correction }\end{array}$ & $\begin{array}{ll}\text { - } & \text { Highlighting an "error" } \\
\text { - } & \text { Circling an "error" } \\
\text { - } & \text { Recording the number } \\
\text { of "errors" made for a } \\
\text { line in the text }\end{array}$ & $\begin{array}{l}\text { - Using editing symbols } \\
\text { to code specific "error" } \\
\text { types } \\
\text { - } \quad \text { Labeling "error" types } \\
\text { under a specific } \\
\text { category }\end{array}$ \\
\hline
\end{tabular}

\section{Sociocultural Conceptualizations of Agency and CF}

As a theory that focuses on collaborations between teachers and students as writing is produced, SCT posits that agency is coproduced relationally through the CF process (Charteris \& Smardon, 2018; Cumming, 2016). SCT views agency as students' control over their actions as writers and students' sense of ownership over their texts (Gorzelsky, 2009; Shapiro et al., 2016). Yet, with this conceptualization, questions linger about which acts are agentive. As critical SCT researchers Moje and Lewis (2007) assert, agency manifests as students' formations and assertions of their linguistic selves within existing power structures.

SCT also offers a number of concepts informing instructors' dialogic responsiveness to $\mathrm{CF}$, including graduated feedback, scaffolding, and negotiation. As a form of $\mathrm{CF}$, graduated feedback aims to provide an appropriate level of guidance needed for the learner to assume agency and engage in revision tasks (Aljaafreh \& Lantolf, 1994). Scaffolding is a concept built upon Vygotsky's (1978) Zone of Proximal Development (ZPD), or the difference between what a learner can do independently versus what a learner can do with guidance. Presuming the existence of a ZPD, scaffolding is individualized task guidance provided by the instructor through a semiotically-mediated means. While scaffolding has been theorized by earlier SCT scholars (i.e., Bruner, 1986; Wood, 1988), van Lier's (2004) conceptualization emphasizes the emergence of learner agency and autonomy. According to van Lier (2004), scaffolding occurs through the conditions of "contingency" and "takeover." Contingency occurs when a guided task initiated by the instructor is subsequently acted upon by the learner, i.e., it becomes a "contingent language act" (van Lier, 1996, p. 172). Takeover occurs as the learner's role in the task increases through focused engagement while the instructor's role diminishes (van Lier, 2004). By involving learners more actively in a process of problem-solving and determining how to revise the targeted linguistic features, many indirect WCF approaches resemble 
the interactive process of scaffolding, contingency, and takeover (Sheen, 2010; Storch \& Wigglesworth, 2010), as the learners' interpretation and the instructors' attentiveness and interpretation are both involved.

Emphasizing the interactive nature of learning, negotiation emerges as a crucial concept whereby learners modify their texts collaboratively. Negotiation of $\mathrm{CF}$ is a process occurring during oral interactions between the learner and instructor. According to Nassaji (2017), negotiation includes interactional strategies such as "repetition, clarification requests, [or] confirmation checks" (p. 116) used by teachers or students. While much of the research on negotiation has focused on learners' oral errors, Nassaji (2017) summarizes studies supporting the effectiveness of negotiation in response to L2 students' written errors. In such contexts, the instructor supports the learner in clarifying meaning in order to build a coherent text. Scaffolding is therefore evident in the negotiation process as the instructor provides individualized guidance, allowing the learner to increase engagement in their revision task.

\section{Limitations of WCF and SCT}

While concepts from WCF and SCT literature have provided the instructor and others teaching L2 writing with important tools to deliver a support system to learners, this paper also maintains that it is important for instructors to critically examine both theories by considering their deficit assumptions.

Firstly, while "error" is a foundational concept for WCF, it is also a contested term among some composition scholars, who argue that L2 writers' deviation from the standard variety does not necessarily constitute "error" (see for example, Horner et al., 2011; Zawacki \& Habib, 2014). While all writers make errors, instructors' perceptions of "error" may emerge as socially-constructed responses to students' dialectal differences or register choices (Matarese \& Anson, 2010). Therefore, as Zawaki and Habib (2014) suggest, critically aware instructors often experience dilemmas "in deciding what constitutes [perceived versus actual] error" (p. 183). Some will constitute actual "errors" as those which (a) are "treatable" (i.e., the error can be easily named and a rule can be taught) or (b) interfere with the comprehension of the text (Ferris, 2011). However, to avoid deficit thinking about students' language differences, writing instructors can alternatively adopt a linguistic orientation, whereby "errors" are interpreted as "linguistic features" (Johnson \& VanBrackle, 2012) or "linguistic hybridity" within students' texts.

Secondly, scaffolding, as a foundational SCT concept, may also presume a deficit orientation, placing an onus on the teacher, as the "expert," to address the linguistic deficiencies of the learner. However, expertise is not unilateral. In one case study focusing on dialogic feedback on L2 writing, Merkel (2018) demonstrates that both the teacher and the L2 writer developed new understandings of linguistic and content knowledge through interaction. 
Scaffolding also presumes that agency is coproduced relationally between students and teachers (Charteris \& Smardon, 2018). However, agency is not always evenly distributed. For instance, in a study of student responses to teacher feedback, Kang and Dykema (2017) show that while some students exerted agency by resisting teacher feedback, others simply complied with feedback, perceiving it as a one-way conversation. Therefore, the social roles teachers assume in the CF process allow them to maintain a degree of dominance that cannot be fully equalized, despite their intentions (Kang \& Dykema, 2017).

Taking a "multicultural approach" to the "idiosyncratic styles" often exhibited in L2 students' writing, Lu (1994) explains how "error" negotiation can be reconceptualized as an agentive process allowing students to "explore the full range of choices [available] including those excluded by the conventions of academic discourses" (p. 447). Some students in Lu's classroom playfully appropriated the unconventional form "can able to" after closely reading a student writing sample containing it. Lu subsequently asked students to distinguish the particular meanings that readers associate with the terms "can," "be able to," and "can able to" in different contexts, prompting students to examine conflicts "between the codes of Standard English and other discourses" (p. 455). While many students eventually preferred to reproduce the more conventional form "is able to," the negotiation process remained significant, enabling students to make active choices in reproducing dominant forms.

\section{Methodology}

\section{Contextualizing Approaches to $C F$}

Examining the literature alongside her previous practices, the instructor determined that direct approaches (i.e., rewriting unconventional linguistic features) would be incongruent with her emerging praxis. Instead, she opted for indirect approaches in this study. Over the course of four writing units, she identified at least one sentence in each student's first draft, suggesting the student revise it. In her selection process, she considered moments where she experienced difficulty making meaning. Following Ferris' (2011) guidelines, she prioritized sentences containing "treatable" or "frequent errors" while ignoring other issues. As she read students' drafts, she kept a running list of common grammatical, lexical, and mechanical issues, and corresponding resources explaining each issue. Issues included sentence fragments, subjectverb agreement, and parallelism.

Aiming to provide students with more information to help revision, she provided explicit, indirect WCF for each identified sentence. To make WCF more explicit, she directed students to explanatory resources. She often 
prompted students to visit Lunsford's (2016) EasyWriter, an editing manual purchased for the course. Her practice was to highlight a sentence with a comment stating, "See EasyWriter section on $\mathrm{x}$ (issue), page y to get an idea of how you might revise this sentence." When she found an issue not explained in the textbook, she supplied a web resource instead.

However, WCF was not the only way she directed students' attention to form in their texts. Goldstein (2005) argues that teachers should build explicit connections between feedback and classroom instruction. Therefore, after providing WCF, the instructor included a classroom activity at the end of each curricular unit involving face-to-face negotiations of sentence-level features. On this day, she arranged students into small groups for a "proofreading workshop." During the workshop, students examined a few sentences written by their peers within a shared Google document. On some occasions, the instructor preselected sentences (that she had not previously commented on), and on other occasions, students selected their own sentences. The proofreading document included a chart with four columns, as shown in Table 2:

Table 2

Proofreading Chart

\begin{tabular}{llll}
\hline Original sentence & Issue & $\begin{array}{l}\text { Resource explaining the } \\
\text { issue }\end{array}$ \\
\hline
\end{tabular}

During the activity, peers negotiated revisions of the selected sentences together. CF studies have shown that teachers' interventions and structuring of activities have an impact on students' revision behaviour during peer negotiation (Storch, 2017). By asking students to name the issue and provide resources to their peers, peer negotiations mirrored the instructors' WCF practices. Students were often able to suggest revisions to their peers' sentences, but many experienced difficulties identifying issues and resources. The instructor therefore took an active role: circulating to address questions, locate resources, and participate in negotiations.

\section{Research Design}

This self-study qualitatively examines six critical incidents (Brookfield, 1990) that occurred within the context of the instructor's classroom over a 16-month period. In consultation with the second author, the instructor chose selfstudy methodology because she was concerned with better understanding her practice as an L2 instructor through reflection (LaBoskey, 2004), but also with making a contribution to a professionalized knowledge base in education (Pinnegar \& Hamilton, 2009). To promote reflective practice, selfstudy involves input from students "with regard to the aspect of our practice under investigation" (LaBoskey, 2004, p. 848), in an effort to learn from 
students how to better teach them. Another collaborative aspect of self-study design involves the input of other researchers as "critical friends" who help teacher researchers to develop new interpretations of their own experiences (Pinnegar \& Hamilton, 2009). The second author assumed the "critical friend" role, offering thoughts on the critical use of theory and the interpretation of data. These contributions were collaboratively incorporated into the article.

\section{Setting and Participants}

The study took place within a developmental writing course (ENG 101) taught by the first author at Westpond University, a pseudonym for a large public university in the Northeastern United States. ENG 101 was a prerequisite course to Westpond's first-year college writing course (ENG 102). ENG 101 was a credit-bearing course providing a smaller pool of students with an additional semester acclimating to academic writing practices before attending ENG 102. Students' placement was determined through an internal writing placement exam. It was not considered an ESL course; however, 77\% of students attending sections taught by the instructor were L2 writers. As a diversity course, essay assignments asked students to critically engage with readings on topics such as race, privilege, and linguistic identity. Assignments invited students to interrogate systems of power, privilege, and schooling in and outside U.S. contexts, while exploring their ethnolinguistic identities. It is within these aims that the instructor approached CF tentatively, allowing for students to engage with it critically (as data subsequently indicate).

While the study involved a larger number of participants, due to space constraints, the voices, writing, and experiences of four students are represented here. All four were first-year students at Westpond, who at the time of the study attended different sections of ENG 101 taught by the instructor. Here critical incidents propelled the data collection and the focal student selection (Halquist \& Musanti, 2010). In other words, the instructor chose to focus on these students because they all experienced critical incidents with CF. They all displayed "some degree of [memorable] conflict" with CF, which stimulated further reflection from the researchers and the participants (Halquist \& Musanti, 2010, p. 451). Table 3 summarizes their backgrounds. 
Table 3

Participants

\begin{tabular}{lllll}
\hline Pseudonym & Gender & $\begin{array}{l}\text { Admission } \\
\text { status }\end{array}$ & $\begin{array}{l}\text { Other known } \\
\text { Languages }\end{array}$ & $\begin{array}{l}\text { Country of } \\
\text { family origin }\end{array}$ \\
\hline $\mathrm{Ai}$ & Female & International & Mandarin & China \\
$\mathrm{Hemant}$ & Male & International & Hindi & India \\
Alejandro & Male & Domestic & Spanish & Mexico \\
Roseline & Female & Domestic & $\begin{array}{l}\text { French, Haitian } \\
\text { Creole }\end{array}$ & Haiti \\
\hline
\end{tabular}

\section{Data Collection}

A range of data sources were first generated and collected from classroom activities and then analyzed to triangulate evidence about students' responsiveness to differing forms of $\mathrm{CF}$. Some data sources were generated by the instructor, including $~ 50$ written journal entries (documenting her $\mathrm{CF}$ exchanges with students in the classroom), teacher feedback (WCF on student writing), and lesson materials. Other students' data sources were generated, including writing samples (three drafts for each of four essays) and surveys (administered at the beginning of each semester). We relied exclusively upon these classroom-generated data sources to represent the instructor's firsthand accounts providing negotiated CF to Alejandro and Roseline. A few months after their course experience concluded, the instructor additionally conducted interviews with $\mathrm{Ai}$ and Hemant, asking them to retrospectively reflect on their experiences with CF. Only two students could later be reached for interviews. However, as we describe in the subsequent section, the first four incidents involving Ai and Hemant foreground the students' perspective, whereas the last two incidents involving Alejandro and Roseline foreground the instructor's perspective.

\section{Critical Incident Analysis}

Self-study does not prescribe a singular method for data selection and analysis, but rather opens possibilities for any method enabling teachers to answer their questions, engage in reflective thinking about their actions, and bring about transformation to their own practices (Williams \& Grierson, 2016). To provoke reflection on our CF practices as L2 teachers, we relied on "critical incidents" as our unit of analysis, and utilized critical incident analysis (CIA) to guide our selection and interpretation of data involving students' engagement with both indirect WCF and negotiated oral CF (Halquist \& Musanti, 2010). "Critical incidents" are salient occurrences experienced by the teacher or others, which prompt reflection and inform classroom practice 
(Farrell, 2013; Schön, 1987; Williams \& Grierson, 2016). Halquist and Musanti (2010) observe that "small events, sometimes even unnoticed situations, could turn into critical incidents" (p. 450) when significant meaning is ascribed to them.

Halquist and Musanti (2010) offer several criteria which we drew upon to select the six critical incidents (CIs) analyzed in this paper. Firstly, CIs often illuminate "some degree of conflict" for the teacher or students, thereby making them memorable (p. 451). All six incidents meet this criterion. Secondly, CIs can offer participants "opportunities to identify, or make visible, aspects of their own lives and/or practice that may be hidden or have gone unnoticed" (p. 455). The first four incidents, which focus on Ai's and Hemant's perceptions of past CF experiences, meet this criterion. In retrospective interviews, $\mathrm{Ai}$ and Hemant re-examined and critiqued their past CF experiences. Thirdly, teachers may select incidents that surprised them, as to become the "stimulus for reflection" on their practice (p. 451). The last two incidents, the instructor's account of Alejandro's and Roseline's contrasting experiences with negotiated oral CF within the classroom, meet this criterion.

While the selected incidents may be small, the analysis of each renders it as "critical." This rendering involves the researcher in looking at the power relationships and the wider social contexts that produce it (Halquist \& Musanti, 2010). Particularly in feedback studies, Kang and Dykema (2017) offer that teachers need to be aware of how power manifests through interpersonal relationships within the feedback process. Viewing students as agents who are able to "negotiate power and identity and develop autonomy as writers," (Kang \& Dykema, 2017, p. 9) our CIA foregrounds how students resist or yield to perceived authority depending on the situation (Halquist \& Musanti, 2010). Our CIA also examines students' discourse about CF, foregrounding their engagement and perceptions of $\mathrm{CF}$.

\section{Results and Discussion}

Collectively, findings illuminate the challenges and affordances students associate with different $\mathrm{CF}$ forms. CIAs also highlight how negotiated CF enables students to assert their agency. The three thematic sections that follow represent (1) Ai's responses to indirect CF, (2) Hemant's negotiation of indirect WCF, and (3) Alejandro's and Roseline's contrasting responses to negotiated $\mathrm{CF}$.

(1) $A i^{\prime}$ s responses to indirect CF

Two CIs showcase Ai's evolving perceptions about indirect CF. 
Critical incident 1: Ai seeks CF from the Writing Center. As an ESL writer, Ai identifies a strong desire to receive CF on her sentences. After taking ENG 101 with the instructor in the fall of 2018, she took ENG 102 with a different instructor the subsequent semester.

Noticing that the ENG 102 instructor did not provide CF, Ai visited the Writing Center (WC) at Westpond on several occasions. Ai was introduced to the WC (which provides individual consultations to students) during ENG 101 , when a WC representative visited the classroom. During each visit to the WC, Ai requested $\mathrm{CF}$, which she defined as feedback on "grammar and word choice." In Extract 1, Ai recounts her recurrent experiences receiving implicit oral CF from WC tutors. In this recurrent scenario, tutors indicated the presence of error within particular sentences by repeatedly pointing each one out and stating, "it's really weird" (Interview, 2/15/19; line 7). In her recount, Ai illuminates conflicts that emerge for her as a learner during negotiated $\mathrm{CF}$ exchanges (i.e., lines 9,17 ), and makes visible small aspects of her experience that might have otherwise gone unnoticed (Halquist \& Musanti, 2010):

\section{Extract 1: Challenges with implicit CF}

1 E: And so when you went there,

2 you told them what you wanted to work on, right?

3 What were you looking for when you went there?

4 A: Just sentence.

5 Maybe I want to seem like I write in the local way,

6 but actually they will not revise my sentence.

7 They will tell me it's "really weird."

8 But they will not revise the sentence,

9 so I cannot get the point.

$10 \mathrm{E}$ : So you had to figure it out?

11 A: Yeah,

12 but I think it's a really good sentence!

13 So I don't know....

14 They just talk to me.

15 [They tell me] I need to revise this sentence or revise [that] sentence.

16 It's always [this way],

17 but I don't know how I can figure out,

18 like how I can revise that.

19 E: So you didn't feel like you got what you were looking for

20 when you went to the writing center?

21 A: Yeah.

(Interview, 2/15/19).

In Extract 1, Ai's re-examination of her CF experiences allows her to critique the way things normally operate at the WC and engage in thoughtful 
reflection about her needs as a learner (Halquist \& Musanti, 2010). Her recollection shows a mismatch between her own expectations about CF (lines $4-5)$ and the indirect, implicit approaches she experienced (lines 6-8, 14-16). Extract 1 exemplifies how exertions of agency and power are interwoven and complex. On one hand, Ai's agency is exhibited in her initiative to seek CF on her writing. Yet on the other hand, Ai appears to relate her linguistic self to "local" English and the WC tutors in unequal ways. In other words, seeking help from tutors to "write in the local way" (line 5) emerge from her understanding that certain textual modifications are valued in academic writing. Even though Ai cannot "figure out" how to revise her sentences, she does not indicate asking tutors for further explanation. Her apparent silence shows "the workings of power dynamics in feedback practices" (Kang \& Dykema, 2017, p. 7) whereby instructors maintain a higher power distribution during CF. For example, Ai later explains that she possesses limited authority as a writer as she is "not confident about writing skills." She also states that "Chinese people don't always have a lot of critical thinking" and "love to accept" feedback without questioning instructors (Interview, 2/15/19).

Critical Incident 2: Ai interprets explicit WCF. Ai experienced challenges not only with tutors' implicit CF but also with the instructor's explicit WCF, which she explained later during her retrospective interview. During ENG 101, Ai recalled that EasyWriter was a "very important" resource providing examples of how to revise sentences. While she often comprehended the book's explanations, she still encountered difficulty when trying to "figure out the problem" with her own sentences, and she attests that sometimes she "cannot handle" revising sentences using only the book (Interview, 2/15/19).

Reflecting on her experience with explicit WCF, Ai re-reads a comment inserted into one of her drafts (which she had successfully revised):

Ai's original sentence: Beverly Daniel Tatum writes some examples to show us how people racially, religiously, or socioeconomically.

Explicit WCF: See the EasyWriter section on sentence fragments (p. 10) to get an idea of how you might revise this sentence.

Ai's revised sentence: Beverly Daniel Tatum writes some examples, which use appeal to ethos, logos, and pathos to show us how people act racially, religiously or socioeconomically.

In Extract 2, Ai explains her complex perceptions of this WCF. As she is prompted to revisit the comment with her instructor, Ai engages in a collaborative process of rendering an incident (which may have otherwise remained unnoticed) as critical by looking back on it. This collaborative rendering enables both $\mathrm{Ai}$ and the instructor to construct new knowledge about the feedback process (Halquist \& Musanti, 2010). 


\section{Extract 2: Perceptions of explicit WCF}

1 E: So when you see that feedback,

2 what is your reaction to it?

3 A: I can just improve my English grammar myself.

4 It's not just only you tell me how to revise,

5 or you just completely help me,

6 like you revise this sentence right.

7 I think I can just know.

8 I can try to deep learn about how I can fix this,

9 and when I miss,

10 I will just remember more clearly.

$11 \mathrm{E}$ : So in this example you changed the sentence correctly.

12 You inserted a verb in there.

13 A: Yeah.

14 E: So do you think this strategy is helpful?

15 Is it helpful to look at a specific section in the textbook

16 that explains a particular grammar issue?

17 Does it help you to think about your sentences?

18 A: Uhhm,

19 I think a little bit,

20 because I always forget to add something in my sentence.

21 Because it's not my first language,

22 so I just try to translate.

23 But for some [it seems] like we['re] talking Chinese,

24 but we don't use some of this [English] grammar.

25 So we cannot very clearly use the grammar in English.

26 So maybe it's useful to revise my writing,

27 but it's not helpful to build up [grammar knowledge] in my head I think.

In Extract 2, Ai expresses ambivalence towards the WCF. While she begins by characterizing her engagement with the comment as "deep learn[ing]" (line 8), she also hesitates to characterize the comment as "helpful" (lines 14-27). Similar to the previous incident, Ai continues to identify and reflect on her challenges with CF. In her view, WCF occurs after she "translates" ideas from Chinese into English on the page (line 22). WCF remains difficult to interpret because she does not use some English grammar patterns in her L1 (line 24). While she acknowledges that it is "a little bit" helpful to revise her sentences after viewing the textbook (line 19-20), it does not satisfy her language development needs, including "build[ing] up" knowledge of new grammar patterns in her "head," rather than orthographically (line 27). By making this need apparent, Ai simultaneously engages in a "strategic making" of her linguistic self and "the material conditions surrounding" herself (Moje 
\& Lewis, 2007, p. 24); she asserts that print materials tied to WCF complicate her language development.

Yet, as Kartchava (2016) notes, learner beliefs about CF are dynamic, such that they may "change in light of one's situation, emotional state and company" (p. 20). The dynamic nature of Ai's beliefs emerge as the exchange continues in Extract 3. Here, Ai's perceptions about WCF appear to fluctuate as she distinguishes the differing impacts that direct (lines 2-6) versus indirect CF (lines 7-14) have on her revision process:

\section{Extract 3: Responding to explicit WCF}

1 E: So, let me ask you this.

2 If I just corrected the sentence,

3 and I inserted the verb for you,

4 how would you respond to that?

5 Would you notice it?

6 A: No.

7 If I don't revise by myself, maybe I will not notice it.

8 E: But it's also difficult to analyze the sentence

9 and think about how you want to change it.

10 Right?

11 A: Yeah.

12 E: It takes some more time to do that.

13 Right?

14 A: It's worth it, I think.

In Extract 3, Ai exhibits multiplicity in her beliefs about indirect WCF as she considers the effects of direct approaches (lines 1-5). Concluding "it's worth it" (line 14) to correct her sentences independently, Ai asserts her agency; she engages in a "remaking" of her linguistic self (Moje \& Lewis, 2007, p. 19) and affirms her ability to control her own actions as a writer (Shapiro et al., 2016). Rather than viewing fluctuating beliefs as signs of irrationality, Halquist and Musanti (2010) frame such shifts in thought as "turning points for knowing" (p. 453). Turning points expand teachers' and students' knowledge by uncovering multiple "practices, positionalit[ies], and perspectives" (p. 453) that have already been occurring "without detection or acknowledgement" (p. 451).

\section{(2) Hemant's Negotiation of WCF}

Two CIs reveal Hemant's perceptions of CF. In CI 3, Hemant reflects on high school experiences receiving implicit WCF. In CI 4, Hemant negotiates WCF he received during ENG 101.

Critical Incident 3: Hemant compares implicit and explicit WCF. Hemant also perceives $\mathrm{CF}$ as a "helpful" part of writing instruction even when it comes 
to smaller, mechanical details of writing. He recalls that EasyWriter identified a "few common mistakes which people generally" make, including how to work with apostrophes. For Hemant, a sense of agency, control, and facility over text emerge through close attention to finer-grained details (i.e., mechanics, grammar, and word choice). Attention to such matters "add[s] up to making" his writing better, enabling him to "decorate" and make his writing "more efficient" (Interview, 02/07/19).

Similar to Ai, in Extract 4, Hemant recalls difficulties learning from implicit WCF during his secondary schooling. In doing so, he renders such past incidents as critical, illuminating conflicts occurring for him as a learner (Halquist \& Musanti, 2010):

\section{Extract 4: Challenges with implicit WCF}

1 [Teachers] used to circle grammatical errors,

2 or underline sentences which were not correct,

3 or which were having grammatical mistakes and stuff...

4 They did not write what was the correct thing,

5 so it was very difficult for us to realize

6 what the error was in that particular thing.

7 Sometimes it was very obvious:

8 like you made a spelling mistake or something,

9 which you can clearly see,

10 but in terms of grammar,

11 I would say it's kind of difficult to realize what the mistake is.

By re-examining past experiences with WCF, Hemant engages in reflection about his needs and abilities as a learner in Extract 4. He distinguishes spelling correction as more "obvious" to self-correct (line 7), but "grammar" as more "difficult to realize" how to correct without explicit explanation (lines 10-11).

In Extract 5, Hemant therefore attests that he appreciates the explanations provided in EasyWriter when revising his sentences:

\section{Extract 5: Processing explicit WCF}

$1 \mathrm{H}$ : [Without this resource] It might be that I would have just changed [my sentence],

2 and not understood why I had changed it,

3 but when I read that entire portion [in the book],

4 and I did research on my own,

5 I tried to understand what the problem was in this particular part....

6 It was a better learning process,

7 than if you would had given it to me directly. 
In Extract 5, Hemant indicates that his sense of agency and ownership of his writing (Gorzelsky, 2009) would dissipate if he "changed" his sentences without comprehension (line 2). In contrast, Hemant characterizes his engagement with explicit WCF as a form of "research" (line 4) and "learning" (line 6).

Critical Incident 4: Hemant negotiates WCF. While Hemant appreciates explicit WCF, like Ai, his challenges did not dissipate. While in other instances, Hemant was successful in his uptake of WCF, he was unsuccessful in addressing the target issue (parallelism) in the following instance:

Hemant's original sentence: The white people are benefitted in the color power system in the society, males are considered to be above the other gender groups in the gender power system and an economically well-off person is considered about others in the class power system (Emphasis Added).

Explicit WCF: See the EW section on Parallelism (p. 172-174) to get an idea of how you might revise this sentence.

In response to the WCF, Hemant only made one change in his revisions, replacing the preposition "about" with "above."

In Extract 6, Hemant rereads this WCF, being aware that his revision did not address the issue. As Hemant reflects, he poses a problem with the original sentence (lines 2-3), and verbalizes a possibility for revision (line 4):

\section{Extract 6: Interpreting explicit WCF}

$1 \mathrm{H}$ : One of the things which I'm feeling right now is

2 [It's] a bit big as well.

3 It is a long sentence.

4 And I could have broken down,

5 or maybe in terms of what I'm trying to explain in this.

6 [It] is the comparison between two groups,

7 two opposite groups,

8 so white and then black.

9 Or how a particular group is given a higher social status

10 as compared to the other group.

11 So, I was trying to express that,

12 but [small laugh]

13 right now I feel that the sentence is ...

14 E: It's a complex sentence, for sure.

As the exchange continues in Extract 7, the instructor attempts to scaffold Hemant's understanding of parallelism, and negotiate an alternative revision to the sentence. A range of discursive markers show negotiation 
and scaffolding. For example, the instructor uses a confirmation check, "Right?" (lines 2, 5, 9, 15, 23) to facilitate Hemant's understanding of the new concept (Nassaji, 2017). Hemant's contingency and takeover in the scaffolding process (van Lier, 2004) emerge through discursive markers such as his use of repetition (line 8 ) and identification of the singular verb form in his sentence (line 20):

\section{Extract 7: Scaffolded negotiation}

1 E: So what you have here are three items in a series.

2 Right?

3 And so you have format that's parallel,

4 in the sense that you use, "people are blank."

5 Right?

6 H: Mhmm [softly]

7 E: Males are

$8 \mathbf{H}$ : [Repeats in unison] Males are

9 E: and you have this pattern, right?

10 H: Okay, Mhmm

11 E: So [your pattern includes] an "are"

12 with the verb in the past tense.

13 H: Okay! Mhmm

14 E: There's a noun,

15 [then] verb in the past tense, right?

$16 \mathrm{H}$ : Yeah

$17 \mathrm{E}:$ And it's plural [your noun].

$18 \mathrm{H}: \mathrm{Mhmm}$

$19 \mathrm{E}$ : And then you have [a noun] here, [in] singular form.

$20 \mathrm{H}$ : is

$21 \mathrm{E}$ : is considered.

$22 \mathrm{H}: \mathrm{Mhmm}$

23 E: So that's a little complicated, right?

24 So parallelism is about

25 having whatever pattern you have in the sentence match.

26 Be consistent throughout.

$27 \mathrm{H}$ : Yeah.

Upon gaining an understanding of parallelism in Extract 7, Extract 8 represents a "turning point" for Hemant, which renders the WCF incident as critical for him and triggers reflection on his learning needs (Halquist \& Musanti, 2010). At this turning point, Hemant's agency manifests as he assumes an advocacy role. In Extract 8, Hemant advocates that instructors have a responsibility to provide further correction when students do not uptake WCF (lines 9-12): 


\section{Extract 8: Preferences for CF}

$1 \mathbf{H}$ : If I wouldn't have made any changes to this particular portion,

2 then I would say that

3 I could not realize the mistake,

4 or the way I could improve this particular sentence,

5 which is why I did not make any revision.

6 I feel that in these particular topics, which are much more complex,

7 like this particular part of grammar is not very common.

8 People don't get these errors very often.

9 So I feel that in these particular situations, like if I don't correct these,

10 I would definitely expect you to tell me directly ...

11 You could have written, "You should have written 'are'". .

12 So I feel that would have just made me realize what mistakes I have.

13 E: But you also pointed out

14 that there are multiple possibilities

15 for revising this sentence.

16 Right?

$17 \mathrm{H}:$ Mhmm

18 E: You could have split it into different sentences,

19 and there were multiple possibilities.

20 Right?

$21 \mathrm{H}: \mathrm{Mhmm}$

In Extract 8, power relations continuously shift. Hemant provides $\mathrm{CF}$, stating what he expects the instructor to change (lines 10-11) when he makes an unrealized "mistake" (line 12). By doing so, he exercises agency, making his linguistic self and his desired actions as a writer known to his teacher (Shapiro et al., 2016). However, rather than arriving at a sense of finality, Hemant's assertions unsettle the instructor, presenting a turning point for expanding the possibilities of knowing, and revealing multiple truths (Halquist \& Musanti, 2010). She recalls Hemant began the negotiation by identifying an alternative strategy (splitting the sentence apart; Extract 6; lines 13-21); Hemant had successfully identified an alternative revision strategy, so she questions whether correction is best for Hemant as a learner. In doing so, she repositions herself in the instructional role, using the same confirmatory cues that she used previously, when scaffolding took place (i.e., "Right?"; Extract 7; lines 16-20). Yet by reclaiming instructional authority, she takes an opportunity to dispel the "right" and "wrong" binary (Dufour \& Ahern-Dodson, 2017), indicating that there is more than one "right" strategy to solve a writing problem. 
(3) Alejandro's and Roseline's contrasting responses to negotiated CF

Both of the CIs revealed in this section occurred in the classroom. These two CIs show Alejandro's and Roseline's contrasting responses to negotiated CF. Both instances surprised the instructor as to stimulate reflection (Farrell, 2013).

Critical incident 5: Alejandro responds to negotiated CF. One of Alejandro's essays recounts the ethnolinguistic challenges he encountered during his Latinx youth, growing up on the West Coast of the United States. He explains that during family gatherings, Spanish is predominantly spoken. On such occasions, he remains quiet, only saying a few Spanish words to relatives because he is not fluent in Spanish. Reading this account in Alejandro's first draft, the instructor encountered a puzzling sentence which read:

This would continue every party, unless my close cousins would show up because I have came up from day one with them.

She selected this sentence for a "proofreading workshop," pasting it (alongside four other students' sentences) into a shared document. During class, she asked Alejandro and his groupmates to read each other's sentences and make revision suggestions. Immediately recognizing his sentence, Alejandro raised his hand in protest, questioning whether it needed revision. He explained, "That's just how we say it," implying that his sentence should stay the same. She then suggested that Alejandro keep the vernacular phrase the same, offset it with quotation marks, and use parentheses to explain the meaning to unknowing readers (Journal, 2/11/19).

Alejandro then revised the sentence to read:

This would continue every party, unless my close cousins would show up because I have "came up from day one" (Vernacular used to describe that my cousins and I have been through the good and the bad together since the day we were born) with them.

Alejandro's agency emerged during this negotiated CF exchange. Alejandro recognized his use of unconventional forms in his writing. The phrase "I have came up" does not apply conventional rules for the present perfect verb tense, and the phrasal verb "came up" also exhibits unconventional semantics. However, by resisting correction, Alejandro maintained a sense of ownership over his text (Gorzelsky, 2009), and he distinguished his linguistic self in opposition to a writerly-self valuing adherence to conventional linguistic forms.

Their brief negotiation broke from traditional notions of scaffolding. When the instructor selected Alejandro's sentence for revision, she perceived it as an "error," presuming Alejandro would change the phrase "I have came up from day one with them" to "I have grown up with them since I was 
born." Yet negotiation revealed that adherence to conventional usage patterns would erase Alejandro's voice in the text and would not support his agency. Negotiation enabled the instructor to learn more about Alejandro's dialectal differences and to break away from deficit perspectives by asking him to supply more information to readers unknowing of such differences. The negotiation makes evident that the instructor's linguistic knowledge base was not superior to Alejandro's. Alejandro, rather, possessed idiolectic expertise, and revision made his knowledge more public to unknowing readers.

Critical incident 6: Roseline responds to negotiated CF. A contrasting experience with Roseline further illustrates the importance of negotiation in supporting student agency. In one essay, Roseline describes her passion for playing the violin, and her participation in her high school's orchestra. Similar to Alejandro, she included a sentence containing "orch dorks," an unconventional lexical item:

On the other hand, some may say that the orchestra environment is orch dorks but actually in reality, we are just people who love playing instruments and love playing music. (Emphasis added).

During independent revision time in class, the instructor approached Roseline about this sentence. She explained that "orch dorks" is a unique, insider term which some readers may not know about. Similar to the advice given to Alejandro, she suggested that Roseline offset the term with quotation marks, explaining it within parentheses. Roseline responded that she had already removed the term because she "hates" seeing red squiggly lines in her word processing software (Journal, 12/9/19).

In contrast to Alejandro, who resisted correction, analysis revealed that Roseline had acted preemptively to correct her sentence. During the negotiation, Roseline exercised agency; she articulated her choice (to remove the term "orch dorks") and explained her rationale for doing so (Shapiro et al., 2016). Roseline distinguished her linguistic self as a writer who defers to the authority of computer-generated CF. While Roseline expressed reluctance to keep her idiolectic term, she later elected to follow part of the instructor's recommendation. She included her idiolectic term, "orch dorks," in quotation marks but did not explain its meaning further.

The negotiation illustrates how Roseline's agency was coproduced relationally in a classroom environment where the instructor's role affords her a degree of dominance that cannot be equalized (Charteris \& Smardon, 2018; Kang \& Dykema, 2017). Given unequal power relationships existing in the feedback process, Roseline eventually opted to use "orch dorks," a term traditionally "excluded by the conventions of academic discourses" at her teacher's encouragement (Lu, 1994, p. 447). Yet she also expressed reluctance given the competing power of other technological tools. The negotiation illustrates complexities that are associated with supporting students' agency 
and choice making in the CF process in the midst of computer-assisted CF tools. As Heift and Hegelheimer (2017) offer, instructors play an important role in teaching learners how to "self-educate" about "how much faith to put into automatically generated error detections" (p. 61) so that their voice is not erased in their texts.

\section{Pedagogical Implications and Conclusion}

This practitioner-led self-study had two main objectives: Firstly, the study asked how ESL writers in a U.S. postsecondary institution perceived differing forms of indirect $\mathrm{CF}$ they received on their writing. Of interest were (a) the implicit forms of CF students experienced in outside contexts, and (b) the explicit forms they received during ENG 101. Findings revealed that two focal participants, Ai and Hemant, problematized implicit forms of CF they received from instructors outside the context of ENG 101; they expressed difficulties interpreting implicit forms to revise their sentences. In contrast, both Ai and Hemant associated affordances with more explicit forms of WCF they received in the context of ENG 101. Both characterized their engagement with such forms as a "learning" process. However, both learners still experienced challenges interpreting explicit WCF and determining revisions for their sentences. Therefore, Ai's and Hemant's perceptions about CF were dynamic and even somewhat contradictory across their differing contexts (Kartchava, 2016). Yet such dynamicity also created "turning points" for students to expand their "possibilities for knowing" about CF together with their instructor (Halquist \& Musanti, 2010, p. 453).

The second objective of the study was to understand how students responded to negotiated oral CF within the context of the ENG 101 classroom. To this end, CIA showed that learner agency emerged through the synchrony of face-to-face negotiation. During negotiation, Lu (1994) encourages instructors and learners to explore a range of choices available for their revisions, even unconventional choices for academic writing. To this end, two focal participants, Alejandro and Roseline, elected to keep unconventional grammatical and lexical items in their writing after negotiating these items with their instructor. Our findings therefore suggest that negotiated feedback enables learners to assert their agency and develop writing identities. However, one limitation of this study is the number of participants/cases. Future studies may therefore explore this assertion further in classroom settings by examining negotiated feedback exchanges together with students' writing products (i.e., multiple drafts).

As this study has explored students' responses to different modalities of $\mathrm{CF}$, it assures Canadian TESL practitioners that there is no "one-size-fits-all" $\mathrm{CF}$ approach in the L2 writing classroom. Rather, different CF modalities afford different kinds of learning opportunities. For instance, Ai explained 
that she would be less likely to "notice" direct WCF and concluded that "it's worth it" to attempt independent revisions to her sentences after receiving indirect WCF. At the same time, Ai asserted that WCF does not address her language development needs, including the need to internalize grammatical patterns distinctive from her L1. To this end, negotiated CF may have better addressed Ai's needs. Therefore, instructors can create a more comprehensive support system for learners by combining differing CF forms (Hyland, 2010). However, findings also show that students' perceptions about CF forms were complex. To be responsive to such complexity, instructors can elicit open communication with students about their CF experiences (Goldstein, 2005). The findings reveal that such communication with students creates opportunities for co-constructing knowledge about learning and revealing multiple experiential truths about CF (Halquist \& Musanti, 2010).

As the study shows agency emerging most visibly through negotiation, teachers may provide opportunities for learners to engage in this form. However, as with other forms, negotiated CF may be approached tentatively as an opportunity not only to facilitate learner language development, but also to facilitate instructor learning. Negotiation afforded the instructor an opportunity to learn about Alejandro's dialectal differences, rather than simply correcting the "error" the instructor perceived. Negotiation provided Alejandro with an opportunity to act as a linguistic expert, explaining his choice to include an unconventional grammatical form in his writing and developing his metalinguistic awareness of the potential meanings conveyed to readers unaware of such dialectal differences.

The paper therefore offers that agency is supported when instructors are mindful of the power dynamics surrounding the CF process and when they institute formative assessment practices which value meaning-making above adherence to language conventions (Balester, 2012). ESL writers have expressed anxieties about receiving low grades in relation to instructor feedback (Best et al., 2015), and there are inevitable power dynamics surrounding the CF process that cannot be equalized despite teachers' intentions (Kang \& Dykema, 2017). Undoubtedly, students' understanding of conventional usages is influenced by how they perceive they are being evaluated by instructors. To equalize the distribution of power, instructors can use rubrics that allow L2 writers to use "creative resources" and linguistic variation in their "language production" (Balester, 2012, p. 71). They can emphasize the importance of building shared understanding with readers. This means that writers engage with unconventional forms mindfully, understanding their responsibility of helping unknowing readers to make meaning of such forms. 


\section{Author Note}

Correspondence concerning this article should be addressed to

Emma R. Britton,

University of Massachusetts Amherst

Department of Teacher Education and Curriculum Studies 813 N Pleasant St

Amherst, MA 01003

Email: ebritton@umass.edu

\section{Acknowledgement}

We would like to thank the students who participated in this research project. We would also like to thank those whose generous comments shaped this paper: Heonsook Cho, Hengyi Liu, Xinyue Zuo, as well as the anonymous reviewers and editors of TESL Canada.

\section{The Authors}

Emma R. Britton is currently a doctoral candidate of Language, Literacy, and Culture in the Department of Teacher Education and Curriculum Studies at University of Massachusetts Amherst, and also an instructor of developmental writing. Her work focuses on multilingual writing pedagogies, critical language awareness, language ideology, and language policy in adult education contexts.

Theresa Y. Austin is a professor of Language, Literacy, and Culture in the Department of Teacher Education and Curriculum Studies at the University of Massachusetts Amherst. Much of her work draws on sociocultural theories to examine language and literacy policies for designing instruction and evaluation of contexts that support multilingual learners' academic and community development.

\section{References}

Aljaafreh, A., \& Lantolf, J. P. (1994). Negative feedback as regulation and second language learning in the zone of proximal development. The Modern Language Journal, 78(4), 465. https://doi.org/10.1111/j.1540-4781.1994.tb02064.x

Baker, W., \& Hansen Bricker, R. (2010). The effects of direct and indirect speech acts on native English and ESL speakers' perception of teacher written feedback. System, 38, 75-84. https:// doi.org/10.1016/j.system.2009.12.007

Balester, V. (2012). How writing rubrics fail: Toward a multicultural model. In A. B. Inoue, \& M. Poe (Eds.), Race and writing assessment. Peter Lang.

Best, K., Jones-Katz, L., Smolarek, B., Stolzenburg, M., \& Williamson, D. (2015). Listening to our students: An exploratory practice study of ESL writing students' views of feedback. TESOL Journal, 6(2), 332-357. https://doi.org/10.1002/tesj.152

Brookfield, S. (1990). Using critical incidents to explore learners' assumptions. In J. Mezirow (Ed.), Fostering critical reflection in adulthood: A guide to transformative and emancipatory learning (pp. 177-193). Jossey-Bass Inc.

Bruner, J. (1986). Actual minds, possible worlds. Harvard University Press.

Charteris, J., \& Smardon, D. (2018). A typology of agency in new generation learning environments: Emerging relational, ecological and new material considerations. Pedagogy, Culture and Society, 26(1), 51-68. https://doi.org/10.1080/14681366.2017.1345975

Cumming, A. (2016). Theoretical orientations to L2 writing. In R. M. Manchón, \& P. K. Matsuda (Eds.), Handbook of second and foreign language writing (pp. 65-88). De Gruyter. https://doi. org/10.1515/9781614511335-006

Dufour, M., \& Ahern-Dodson, J. (2017). Good writers always follow my rules. In C. E. Bal, \& D. 
M. Loewe (Eds.), Bad ideas about writing (pp. 121-125). Digital Publishing Institute.

Farrell, T. S. C. (2013). Critical incident analysis through narrative reflective practice: A case study. Iranian Journal of Language Teaching Research, 1(1), 79-89.

Ferris, D. R. (1995). Student reactions to teacher response in multiple-draft composition classrooms. TESOL Quarterly, 29(1), 33-53. https://doi.org/10.2307/3587804

Ferris, D. R. (2011). Treatment of error in second language student writing (2nd ed.). The University of Michigan Press. https://doi.org/10.3998/mpub.2173290

Goldstein, L. M. (2005). Teacher written commentary in second language writing classrooms. The University of Michigan Press. https://doi.org/10.3998/mpub.6737

Goldstein, L. M. (2016). Making use of teacher written feedback. In R. M. Manchón, \& P. K. Matsuda (Eds.), Handbook of second and foreign language writing (pp. 407-430). De Gruyter. https://doi.org/10.1515/9781614511335-022

Gorzelsky, G. (2009). Working boundaries: From student resistance to student agency. College Composition and Communication, 61(1), 64-84.

Guénette, D. (2013). The pedagogy of error correction: Surviving the written corrective feedback challenge. TESL Canada Journal, 30(1), 117-126. https://doi.org/10.18806/tesl.v30i1.1129

Halquist, D., \& Musanti, S. I. (2010). Critical incidents and reflection: Turning points that challenge the researcher and create opportunities for knowing. International Journal of Qualitative Studies in Education, 23(4), 449-461. https://doi.org/10.1080/09518398.2010.492811

Heift, T., \& Hegelheimer, V. (2017). Computer-assisted corrective feedback and language learning. In H. Nassaji, \& E. Kartchava (Eds.), Corrective feedback in second language teaching and learning: Research, theory, applications, implications (pp. 51-65). Routledge. https://doi. org/10.4324/9781315621432-5

Horner, B., Lu, M., Royster, J. J., \& Trimbur, J. (2011). Language difference in writing: Toward a translingual approach. College English, 73(3), 303-321.

Hyland, F. (2010). Future directions in feedback on second language writing: Overview and research agenda. International Journal of English Studies, 10(2), 171-182. https://doi. org/10.6018/ijes/2010/2/119251

Johnson, D., \& VanBrackle, L. (2012). Linguistic discrimination in writing assessment: How raters react to African American "errors," ESL errors, and standard English errors on a state-mandated writing exam. Assessing Writing, 17(1), 35-54. https://doi.org/10.1016/j. asw.2011.10.001

Kang, H.-S., \& Dykema, J. (2017). Critical discourse analysis of student responses to teacher feedback on student writing. Journal of Response to Writing, 3(2), 6-35.

Kartchava, E. (2016). Learners' beliefs about corrective feedback in the language classroom: Perspectives from two international contexts. TESL Canada Journal, 33(2), 19. https://doi. org/10.18806/tesl.v33i2.1235

LaBoskey, V. (2004). The methodology of self-study and its theoretical underpinnings. In J. Loughran, M. Hamilton, V. LaBoskey, \& T. Russell (Eds.), International handbook of self- study of teaching practices (pp. 817-869). Kluwer Press. https://doi.org/http://dx.doi.org/10.1007/9781-4020-6545-3_21

Lu, M.-Z. (1994). Professing multiculturalism: The politics of style in the contact zone. College Composition and Communication, 45(4), 442-458. https://doi.org/10.2307/358759

Lunsford, A. A. (2016). EasyWriter. Bedford/St. Martins.

Matarese, M., \& Anson, C. (2010). Teacher response to AAE features in the writing of college students: A case study in the social construction of error. In J. B. Smith (Ed.), The elephant in the classroom: Race and writing (pp. 111-136). Hampton Press.

Merkel, W. (2018). Role reversals: A case study of dialogic interactions and feedback on L2 writing. Journal of Second Language Writing, 39, 16-28. https://doi.org/10.1016/j.jslw.2017.11.007

Moje, E. B., \& Lewis, C. (2007). Examining opportunities to learn literacy: The role of critical sociocultural literacy research. In C. Lewis, P. Enciso, \& E. B. Moje (Eds.), Reframing sociocultural research on literacy (pp. 15-48). Lawrence Erlbaum Associates. 
Montgomery, J. L., \& Baker, W. (2007). Teacher-written feedback: Student perceptions, teacher self-assessment, and actual teacher performance. Journal of Second Language Writing, 16(2), 82-99. https://doi.org/10.1016/j.jslw.2007.04.002

Nassaji, H. (2017). Negotiated oral feedback in response to written errors. In H. Nassaji, \& E. Kartchava (Eds.), Corrective feedback in second language teaching and learning: Research, theory, applications, implications (pp. 114-128). Routledge. https://doi.org/10.4324/9781315621432-9

Pinnegar, S., \& Hamilton, M. L. (2009). Self-study of practice as a genre of qualitative research. Springer. https://doi.org/10.1007/978-1-4020-9512-2_4

Razfar, A. (2010). Repair with confianza: Rethinking the context of corrective feedback for English learners (ELs). English Teaching: Practice and Critique, 9(2), 11-31.

Schön, D. A. (1987). Educating the reflective practitioner. Jossey-Bass.

Shapiro, S., Cox, M., Shuck, G., \& Simnitt, E. (2016). Teaching for agency: From appreciating linguistic diversity to empowering student writers. Composition Studies, 44(1), 31-52.

Sheen, Y. (2010). The role of oral and written corrective feedback in SLA. Studies in Second Language Acquisition, 32, 169-179. https://doi.org/10.1017/S0272263109990489

Storch, N., \& Wigglesworth, G. (2010). Learners processing, uptake, and retention of corrective feedback on writing: Case studies. Studies in Second Language Acquisition, 32(2), 303-334. https://doi.org/10.1017/S0272263109990532

Storch, N. (2017). Peer corrective feedback in computer-mediated collaborative writing. In H. Nassaji \& E. Kartchava (Eds.), Corrective feedback in second language teaching and learning: Research, theory, applications, implications (pp. 66-79). Routledge. https://doi. org/10.4324/9781315621432-6

Truscott, J. (1999). The case for "the case against grammar correction in L2 writing classes": A response to Ferris. Journal of Second Language Writing, 8(2), 111-122. https://doi.org/10.1016/ S1060-3743(99)80124-6

van Lier, L. (1996). Interaction in the language curriculum: Awareness, autonomy, and authenticity. Longman.

van Lier, L. (2004). The ecology and semiotics of language learning: A sociocultural perspective. Kluwer Academic Publishers. https://doi.org/10.1007/1-4020-7912-5

Vygotsky, L. (1978). Interaction between learning and development. In M. Gauvain, \& M. Cole (Eds.), Readings on the development of children (pp. 34-40). Scientific American Books. https://doi.org/10.1038/scientificamerican0478-34

Wang, T., \& Jiang, L. (2015). Studies on written corrective feedback: Theoretical perspectives, empirical evidence, and future directions. English Language Teaching, 8(1), 110-120. https:// doi.org/10.5539/elt.v8n1p110

Williams, J., \& Grierson, A. (2016). Facilitating professional development during international practicum: Understanding our work as teacher educators through critical incidents. Studying Teacher Education, 12(1), 55-69. https://doi.org/10.1080/17425964.2016.1143812

Wood, D. (1988). How children think and learn. Basil Blackwell.

Zawacki, T. M., \& Habib, A. S. (2014). Negotiating "errors" in L2 writing: Faculty dispositions and language difference. In T. M. Zawacki, \& M. Cox (Eds.), WAC and second language writers: Research towards linguistically and culturally inclusive programs and practices (pp. 183-210). Parlor Press. 